\title{
Quantifying Climate Forcings and Feedbacks over the Last Millennium in the CMIP5-PMIP3 Models*
}

\author{
A. R. ATWOOD \\ School of Oceanography, University of Washington, Seattle, Washington \\ E. Wu, D. M. W. FRIERSON, AND D. S. BATTISTI \\ Department of Atmospheric Sciences, University of Washington, Seattle, Washington \\ J. P. SACHS \\ School of Oceanography, University of Washington, Seattle, Washington
}

(Manuscript received 20 January 2015, in final form 27 July 2015)

\begin{abstract}
The role of radiative forcings and climate feedbacks on global cooling over the last millennium is quantified in the CMIP5-PMIP3 transient climate model simulations. Changes in the global energy budget over the last millennium are decomposed into contributions from radiative forcings and climate feedbacks through the use of the approximate partial radiative perturbation method and radiative kernels. Global cooling occurs circa 1200-1850 CE in the multimodel ensemble mean with pronounced minima corresponding with volcanically active periods that are outside the range of natural variability. Analysis of the global energy budget during the last millennium indicates that Little Ice Age (LIA; 1600-1850 CE) cooling is largely driven by volcanic forcing (comprising an average of $65 \%$ of the total forcing among models), while contributions due to changes in land use $(13 \%)$, greenhouse gas concentrations $(12 \%)$, and insolation $(10 \%)$ are substantially lower. The combination of these forcings directly contributes to $47 \%$ of the global cooling during the LIA, while the remainder of the cooling arises from the sum of the climate feedbacks. The dominant positive feedback is the water vapor feedback, which contributes $29 \%$ of the global cooling. Additional positive feedbacks include the surface albedo feedback (which contributes $7 \%$ of the global cooling and arises owing to high-latitude sea ice expansion and increased snow cover) and the lapse rate feedback (which contributes an additional $7 \%$ of the global cooling and arises owing to greater cooling near the surface than aloft in the middle and high latitudes).
\end{abstract}

\section{Introduction}

Last millennium temperature reconstructions represent important targets for paleoclimate research owing to their importance in contextualizing recent climate change and separating anthropogenic impacts from natural climate variability. Reconstructions point to two major climate epochs during the preindustrial era: the Medieval Climate Anomaly (MCA; ca. 900-1200 CE)

\footnotetext{
* Supplemental information related to this paper is available at the Journals Online website: http://dx.doi.org/10.1175/JCLI-D-15-0063.s1.

Corresponding author address: A.R. Atwood, School of Oceanography, Box 355351, University of Washington, Seattle, WA 98195. E-mail: aatwood@uw.edu
}

and the Little Ice Age (LIA; ca. 1300-1850 CE) (e.g., Crowley 2000; Jones et al. 1998; Lamb 1965; Mann et al. 2009). Paleoclimate proxy records demonstrate substantial heterogeneity in the timing, amplitude, and spatial extent of the MCA and LIA; thus, these periods are characterized by regionally specific temperature departures from an overall global cooling trend over the last millennium (PAGES 2k Consortium 2013). Temperature reconstructions across the globe generally indicate a cooling trend beginning circa 1200-1500 CE and (though interspersed with periods of warmth) continuing to the nineteenth century, with cooling in North America and the Southern Hemisphere lagging that in the Arctic, Europe, and Asia (Fig. 1; PAGES 2k Consortium 2013; Cunningham et al. 2013; Kobashi et al. 2011; Larsen et al. 2011; Massé et al. 2008; Ogilvie and Jonsson 2001). 


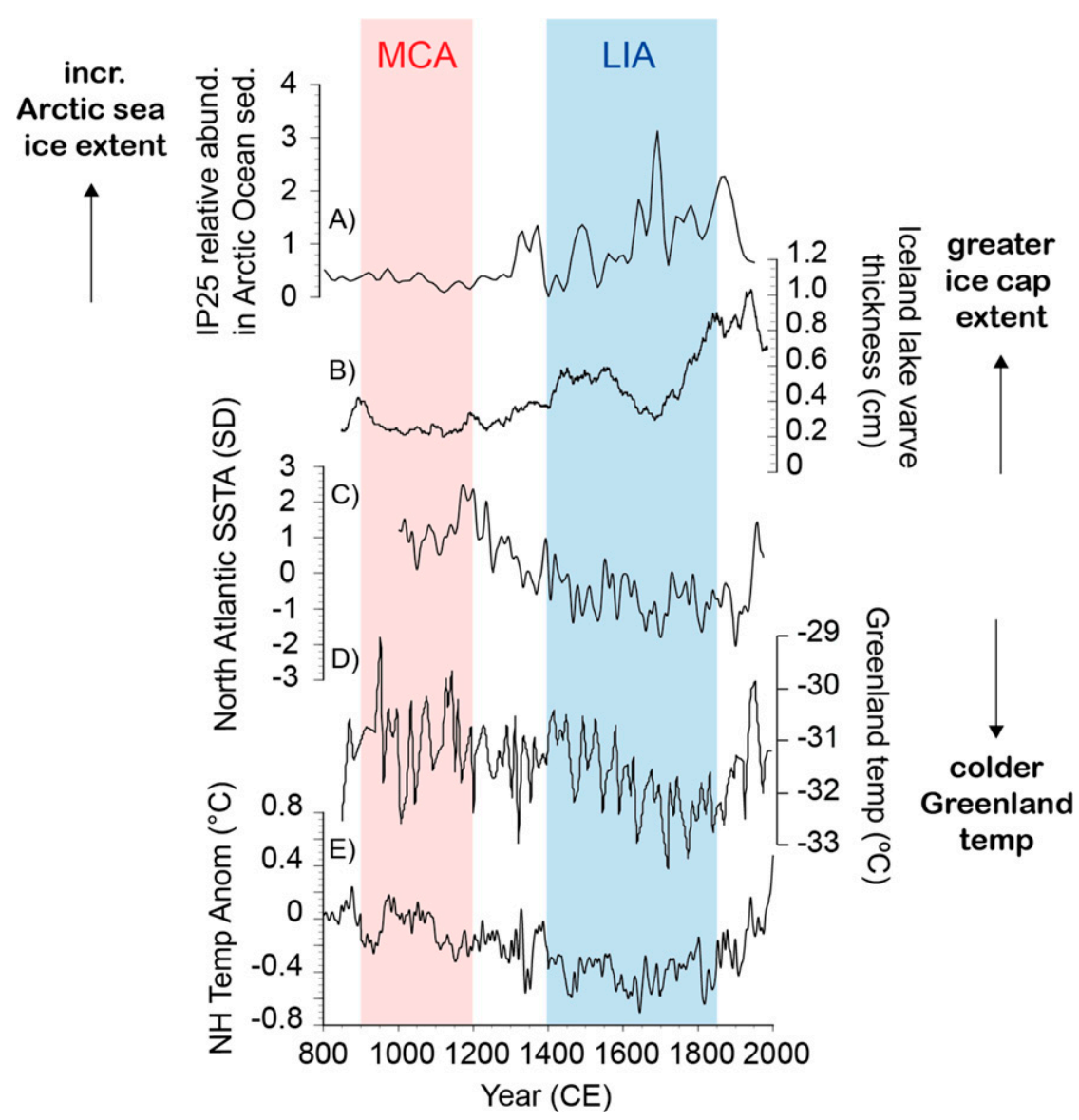

FIG. 1. Proxy records of climate change over the last millennium: (a) changes in Arctic sea ice extent based on the relative abundance of biomarker $\mathrm{IP}_{25}$ in a sediment core from the north coast of Iceland (Massé et al. 2008), (b) ice cap extent in central Iceland from Hvítárvatn Lake sediment varve thickness (Larsen et al. (2011), (c) multiproxy NE Atlantic SST composite (Cunningham et al. 2013), (d) Greenland temperature reconstruction (Kobashi et al. (2011), and (e) NH temperature anomalies based on a multiproxy network and climate field reconstruction method (Mann et al. 2009). Approximate time periods for the MCA (900-1200 CE) and LIA (1400-1850 CE) are highlighted in pink and blue shading, respectively.

The spatial and temporal heterogeneity of the LIA cooling signal is likely the result of a complex array of forcings, feedbacks, and internal variability operating in the climate system (Kaufman et al. 2009; FernandezDonado et al. 2013; Lehner et al. 2013). A number of different forcing mechanisms (including solar, volcanic, land use, greenhouse gas, and orbital forcings) acting in concert with atmosphere, ocean, and sea ice feedbacks have been invoked to explain the cold conditions during the LIA, while internal variability is also thought to have played an important role in temperature variations over the last millennium (e.g., Bianchi and McCave 1999; Bond et al. 2001; Briffa et al. 1998; PAGES 2k Consortium 2013; Crowley 2000; Kaufman et al. 2009; Lean and Rind 1999; Lehner et al. 2013; Mann et al. 1998; Marcott et al. 2013; Miller et al. 2012; Palastanga et al. 2011; Schleussner and Feulner 2013; Schurer et al.
2013; Wanamaker et al. 2012; Zhong et al. 2011). However, the relative contributions of the various forcing and feedback terms to the global and regional cooling signals are still poorly understood. For instance, while some studies have emphasized the role of solar variability on the cooling during the LIA (Lean and Rind 1999; Bard et al. 2000; Bond et al. 2001; Weber 2005; Yoshimori et al. 2005), others have suggested that volcanic aerosols and greenhouse gases had a dominant role (Briffa et al. 1998; Hegerl et al. 2003; Ammann et al. 2007; Schurer et al. 2014). Still others have highlighted the importance of orbital variations (Kaufman et al. 2009) and ocean and sea ice feedbacks (Bianchi and McCave 1999; Miller et al. 2012; Wanamaker et al. 2012; Lehner et al. 2013; Schleussner and Feulner 2013).

Here, we seek to address this issue by quantifying the relative importance of the various climate forcings and 
feedbacks to global cooling during the LIA in the last millennium simulations performed as a part of phase 5 of the Coupled Model Intercomparison Project (CMIP5)Paleoclimate Modelling Intercomparison Project phase 3 (PMIP3). These transient climate model simulations are driven by last millennium boundary conditions and enable detailed examination of the global energy budget to be evaluated over the last millennium (Braconnot et al. 2012; Schmidt et al. 2012; Taylor et al. 2012). However, decomposing the energy fluxes into contributions from individual forcings and climate feedbacks is nontrivial. One approach to quantifying the response of the climate system to individual forcings involves applying a multiple-regression method to proxy-based temperature reconstructions in order to estimate the climatic "fingerprints" of the forcings (Hegerl et al. 2003, 2007). Such climatic fingerprints have also be evaluated from general circulation model (GCM) simulations driven with different forcing datasets and the results compared to the fingerprints from proxybased reconstructions (Schurer et al. 2013, 2014). As a part of this analysis, Schurer et al. carried out individually forced model simulations in order to quantify the role of individual forcings on temperature variability over the last millennium. However, such individually forced experiments are computationally expensive with a fully coupled GCM, and to date, only a limited number of such simulations have been performed. In this study, we adopt an alternative approach to quantifying the mechanisms of LIA cooling that can be applied to a large number of all-forcing GCM simulations. In this study, we quantify the role of the various forcing and feedback mechanisms to global cooling over the last millennium by decomposing the global energy budget of the last millennium simulations in the CMIP5-PMIP3 archive through the use of the approximate partial radiative perturbation (APRP) method and radiative kernels.

\section{Methods}

\section{a. Model simulations and forcings}

In this analysis, we use output from transient climate simulations of the last millennium and from unforced 850-1000-yr-long control simulations with preindustrial boundary conditions from seven different atmosphereocean general circulation models (AOGCMs) in the CMIP5-PMIP3 archive (Braconnot et al. 2012; Taylor et al. 2012). These models are CCSM4 (Gent et al. 2011; Landrum et al. 2013); GISS-E2-R forcing ensemble members r1i1p121 and r1i1p124 (GISS 121 and GISS 124 hereafter; Schmidt et al. 2006), MPI-ESM-P (MPI hereafter), IPSL-CM5A-LR (IPSL hereafter; Dufresne et al. 2013), CSIRO Mk3L version 1.2 (CSIRO hereafter; Rotstayn et al. 2012; Phipps et al. 2012), and HadCM3
(Pope et al. 2000; Collins et al. 2001; Schurer et al. 2013). These model simulations were chosen based on the availability of data at the time of analysis. MIROC-ESM and FGOALS-s2 simulations were omitted because of long-term drifts in global mean surface air temperature in their preindustrial (PI) control simulations. Details of the models, and their external forcing and references, can be found in Table 1, in Masson-Delmotte et al. (2013), and in Flato et al. (2013). Different forcing datasets were imposed in the last millennium simulations of different GCMs, following the protocols of PMIP3 (https://pmip3. lsce.ipsl.fr/wiki/doku.php/pmip3:design:lm:final) as discussed by Schmidt et al. (2012) and outlined in Table 1. The forcings are composed of (from top to bottom in Fig. 2) volcanic aerosols, greenhouse gas $\left(\mathrm{CH}_{4}, \mathrm{CO}_{2}\right.$, and $\mathrm{N}_{2} \mathrm{O}$ ) concentrations, solar radiation associated with changes in orbital configuration and solar output, and anthropogenic land-use changes (not shown).

\section{1) VOLCANIC FORCING}

Reconstructions of volcanic aerosols used in the last millennium simulations (Fig. 2a) are derived from either the Gao et al. (2008, hereafter GRA) dataset of sulfate loading, or the Ammann et al. (2007, hereafter AJS) or Crowley et al. (2008, hereafter CEA) datasets of aerosol optical depth (AOD), as indicated in Table 1 (Schmidt et al. 2011). The CEA dataset is based on 13 Greenland and Antarctic ice cores, and AOD and effective radius are given in 10-day intervals in four equal-area latitude bands. The GRA dataset is based on 54 ice cores, 32 from the Arctic and 22 from Antarctica. Sulfate loading is provided in the GRA dataset as a function of month, latitude in 10 bands, and height from 9 to $30 \mathrm{~km}$ at $0.5-\mathrm{km}$ resolution. Four models (GISS 121, GISS 124, MPI, and HadCM3) prescribed volcanic aerosols in terms of AOD and aerosol effective radius from CEA. CCSM4 prescribed sulfate loading (in Tg) from GRA (Landrum et al. 2013). CSIRO estimated the globally averaged forcing from the CEA dataset of AOD and applied the forcing as a total solar irradiance anomaly (Masson-Delmotte et al. 2013). In IPSL, AOD was prescribed from the AJS dataset, but, because of the details of the implementation, the aerosol extinction coefficients experienced a slow daily decrease subsequent to being updated at the start of each day (J.-L. Dufresne and M. Khodri 2014, personal communication).

\section{2) TRACE GAS FORCING}

Changes in concentration of the principal well-mixed greenhouse gases (GHGs; e.g., $\mathrm{CO}_{2}, \mathrm{CH}_{4}$, and $\mathrm{N}_{2} \mathrm{O}$ ) over the last millennium (Fig. 2d) are related to both natural variations as well as anthropogenic factors in the latter part of the last millennium (Gerber et al. 2003). Reconstructions are derived from high-resolution ice cores in Antarctica 
and smoothed to retain only decadal-scale and longer variations (Joos and Spahni 2008). All models use the same set of GHG concentrations, as described in Schmidt et al. (2011). In addition, one model (MPI) parameterizes ozone variations as a function of changes in solar irradiance based on the results of Shindell et al. (2006).

\section{3) ORBitAl FORCING}

Changes in the top-of-the-atmosphere (TOA) insolation during the last millennium were primarily due to changes in precession. From $850 \mathrm{CE}$ to the present, a $\sim 20$-day shift in perihelion (from 15 December to 4 January) occurred, leading to an increase in insolation in early Northern Hemisphere (NH) summer relative to the late NH summer (Schmidt et al. 2011). Small decreases in eccentricity and obliquity also contributed to the insolation changes. These changes gave rise to a $\sim 3 \mathrm{~W} \mathrm{~m}^{-2}$ decrease in insolation in boreal summer [June-August (JJA)] at $65^{\circ} \mathrm{N}$ through the last millennium (Fig. 2e).

\section{4) SOLAR FORCING}

Changes in total solar irradiance (TSI) are prescribed using either the Vieira et al. (2011, hereafter VSK) or Steinhilber et al. (2009, hereafter SBF) reconstruction as described in Schmidt et al. (2011). In some models, background variations of TSI (variations not tied to the solar cycle) are taken from Wang et al. (2005, hereafter WLS), as indicated in Table 1. TSI anomalies from these three products are shown in Fig. 2 f.

\section{5) LAND-USE FORCING}

Reconstructions of land use and land cover are available for the last three centuries based on published maps of agricultural areas and for earlier periods based on scaling agricultural activity with population on a per country basis. The resultant dataset provides annual maps of cropland, and C3 and C4 pastures, which influence the surface albedo, water cycle, surface roughness, and soil characteristics (Pongratz et al. 2008, hereafter PEA; Schmidt et al. 2011). Although implementation of a given land cover forcing varies across models, all model simulations analyzed in this study either used land cover forcings from PEA or maintained constant land cover (taken from the preindustrial control runs; Table 1).

\section{b. Description of the APRP method}

The APRP method enables changes in TOA shortwave (SW) energy fluxes to be decomposed into individual radiative forcing and climate feedback terms (Taylor et al. 2007). The APRP method has been used to perform climate feedback analyses in a variety of Last Glacial Maximum, historical, and future climate simulations (e.g., Crucifix 2006; Yoshimori et al. 2011; Hwang et al. 


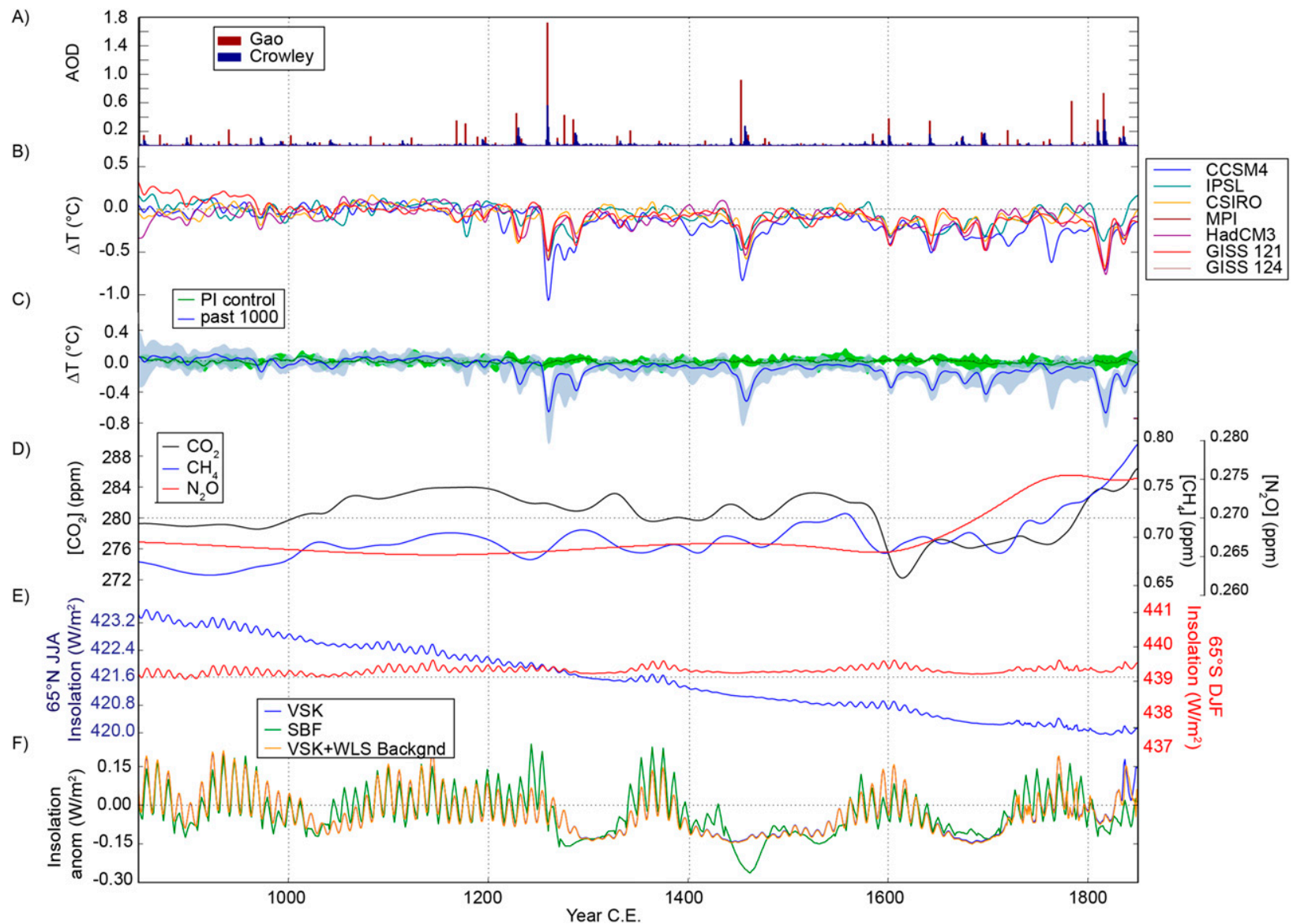

FIG. 2. Climate forcings and global surface air temperature through the last millennium in the CMIP5 models: (a) AOD from CEA [blue bars; Crowley (2000)] and estimated from GRA [red bars] by dividing sulfate loading by $150 \mathrm{Tg}$ (Stothers 1984), (b) globally averaged surface air temperature anomaly (relative to 950-1200 CE) in each last millennium simulation, and (c) globally averaged surface air temperature anomaly for the multimodel ensemble mean of the last millennium simulations (blue) and the control simulations (green) where solid lines represent the multimodel mean and shading represents $1 \sigma$. Temperature anomalies are calculated relative to years 100 350 in each dataset and annually averaged data were smoothed with a Gaussian filter with $\sigma=3 \mathrm{yr}$. (d) Concentrations of $\mathrm{CO}_{2}, \mathrm{CH}_{4}$, and $\mathrm{N}_{2} \mathrm{O}$. (e) Changes in insolation at $65^{\circ} \mathrm{N}$ in JJA (blue) and $65^{\circ} \mathrm{S}$ in December-February (DJF; red). (f) Globally averaged insolation anomalies (relative to 950-1200 CE) for the solar forcing datasets outlined in Table 1.

2013; Masson-Delmotte et al. 2013). APRP is based on a simple, single-layer, shortwave radiative model of the atmosphere, in which the influence of changes in surface albedo, shortwave absorption, and scattering on the topof-the-atmosphere energy budget are diagnosed at every grid cell from all-sky and clear-sky GCM output. APRP analysis relies on the use of a single-layer radiative transfer model that is tuned to mimic the radiation code of the GCM. Specifically, three parameters in the singlelayer model are calculated (the surface albedo, atmospheric scattering coefficient, and atmospheric absorption coefficient) to ensure that the surface and top-of-theatmosphere shortwave fluxes are consistent with those in the GCM. These single-layer-model parameters are calculated for two time periods, representing the control and perturbed conditions. These parameters are then individually perturbed in the single-layer model by the amount they change between the control and perturbed periods of the GCM simulation, and the influence of these changes on the TOA shortwave flux in the single-layer model is calculated. In this way, the single-layer model enables the effects of changes in surface albedo, atmospheric absorption, atmospheric scattering, and clouds to be isolated from one another using a simple and efficient method. Importantly, these calculations allow for an estimate of volcanic forcing to be obtained from the change in shortwave noncloud scattering (see section 2d).

This method is similar to the partial radiative perturbation (PRP) method, which is the more accurate approach for calculating feedbacks (as it is based on applying a given perturbation of a climate feedback variable to an offline radiation code of the model and determining its feedback 
strength from the subsequent change in TOA flux). However, whereas the PRP method requires running the GCMs radiation code offline with the various radiation properties individually perturbed, APRP calculations are far less computationally expensive and require far less data from the full GCM simulations (only monthly clear-sky and full-sky radiative flux fields at the surface and TOA are needed). In addition, comparison between full PRP and APRP analyses of global warming and Last Glacial Maximum simulations with two GCMs demonstrated that the differences between them were typically only a few percent (Taylor et al. 2007). Further details of the APRP method can be found in Taylor et al. (2007).

\section{c. Description of the radiative kernel method}

Because of the sensitivity of the radiation balance to the vertical distribution of atmospheric water vapor, temperature, and clouds, the simple, single-layer atmosphere model used in the SW APRP calculations is generally not appropriate for LW feedback analyses (Yoshimori et al. 2011). We must thus adopt a different method for decomposing TOA LW fluxes from the last millennium simulations. Under the radiative kernel technique of Soden et al. (2008), climate feedbacks are quantified based on the TOA radiative response to a small change in the climate feedback variable. Climate feedbacks are represented as the product of two terms: the first is the radiative kernel, which is a weighting term that describes the TOA flux perturbation due to a standard change in a particular climate feedback variable (e.g., specific humidity), and the second is the change in that climate feedback variable in the full GCM simulation. The kernels used in this analysis are from Shell et al. (2008) based on the CAM3 offline radiative transfer model with a CAM3 present-day-climate base state. Available kernels include a surface albedo kernel, LW water vapor kernel, LW surface skin temperature kernel, LW atmospheric temperature kernel, and $\mathrm{LW} \mathrm{CO}_{2}$ kernel. For each feedback there is a clear-sky kernel (for which cloud-free conditions were used in the radiative transfer calculations) and an all-sky kernel (which includes the effects of clouds in the radiative transfer calculations). Because of strong nonlinearities, cloud feedbacks cannot be evaluated directly from a radiative kernel but instead are calculated by adjusting the cloud radiative forcing to account for cloudmasking effects (using the difference between the all-sky and clear-sky kernels) as outlined in Soden et al. (2008). Studies have shown that radiative kernels are dependent on the forcing and background climate state, but are highly similar when calculated from different models under a given base state (Soden et al. 2008; Yoshimori et al. 2011; Vial et al. 2013). Comparison between full PRP, APRP, and radiative kernel methods in Last Glacial
Maximum and $2 \times \mathrm{CO}_{2}$ simulations with an atmospheric GCM coupled to a slab-ocean model suggest that differences between PRP and radiative kernel feedbacks tend to be slightly larger than those between PRP and APRP feedbacks (Yoshimori et al. 2011).

\section{d. Calculation of forcings and feedbacks using APRP and radiative kernel methods}

As described in section 2c, quantification of the forcing and feedbacks in the CMIP5-PMIP3 last millennium simulations was estimated using the above APRP method to decompose changes in the global SW TOA energy budget and using the radiative kernel method to decompose changes in the global LW TOA energy budget (Shell et al. 2008; Soden and Held 2006; Soden et al. 2008). The response of the TOA global energy budget to a radiative forcing can be described as follows:

$$
\Delta R_{\text {imbal }}=\Delta F+\Delta R_{\text {resp }},
$$

where $\Delta F$ represents the radiative forcing, $\Delta R_{\text {resp }}$ represents the TOA energy fluxes due to climate feedbacks (i.e., the climate response), and $\Delta R_{\text {imbal }}$ represents the remaining imbalance in the earth's TOA energy budget. The TOA and surface energy fluxes are defined as positive when directed into the atmosphere. The change in the net TOA energy flux can then be decomposed into the change in absorbed shortwave $\left(\Delta R_{\mathrm{SW}}\right)$ and the change in outgoing $\mathrm{LW}\left(-\Delta R_{\mathrm{LW}}\right)$ :

$$
\Delta R_{\text {imbal }}=\Delta R_{\mathrm{SW}}+\Delta R_{\mathrm{LW}} .
$$

\section{1) THE SHORTWAVE ENERGY BUDGET}

The SW energy budget at the TOA can be described as

$$
R_{\mathrm{SW}}=S_{o}(1-A),
$$

where $S_{o}$ is the solar constant (in $\mathrm{W} \mathrm{m}^{-2}$ ) and $A$ is the planetary albedo. Following a perturbation, the new SW budget is

$$
\left(R_{\mathrm{SW}}+\Delta R_{\mathrm{SW}}\right)=\left(S_{o}+\Delta S\right)[1-(A+\Delta A)] .
$$

Hence, the change in TOA SW $\left(\Delta R_{\mathrm{SW}}\right)$ is then

$$
\Delta R_{\mathrm{SW}}=\underbrace{\Delta S(1-A)}_{\Delta F_{\text {solar }}}-\underbrace{S_{o} \Delta A}_{\Delta R_{A}}-\Delta S \Delta A,
$$

where $\Delta F_{\text {solar }}$ is the change in solar forcing (because of a change either in orbital configuration or in solar output), $\Delta R_{A}$ is the change in TOA SW due to a change in planetary albedo, and $\Delta S \Delta A$ is the residual. Solar forcing was further decomposed into changes in solar output 
and changes in orbital configuration using equations from Berger (1978). The change in planetary albedo is

$\Delta A=\Delta A_{\alpha}+\Delta A_{\text {cloud }}+\Delta A_{\text {clear,scatter }}+\Delta A_{\text {clear,abs }}+\Delta A_{\text {resid }}$.

The terms on the rhs are changes in the planetary albedo due to the SW climate forcings and feedbacks; they are estimated by the APRP method of Taylor et al. (2007), and $\Delta A_{\text {resid }}$ is the residual. We interpret the change in clear-sky scattering to be forcing by volcanic aerosols,

$$
\Delta F_{\text {volc }}=-S_{o} \Delta A_{\text {clear,scatter }} .
$$

Land-use forcing was estimated by averaging $\Delta A_{\alpha}$ over regions that underwent agricultural changes (i.e., changes in the fractional area of cropland and/or $\mathrm{C} 3$ or $\mathrm{C} 4$ pasture) during the LIA relative to the MCA,

$$
\Delta F_{\text {landuse }}=-S_{o} \Delta A_{\alpha, \mathrm{ag}} .
$$

The remaining shortwave feedback $\Delta R_{\mathrm{SW}}$ terms are calculated as

$$
\Delta R_{\mathrm{SW}}=\left\{\begin{array}{ll}
-S_{o} \Delta A_{\alpha, \text { non-ag }} & \text { surface albedo feedback } \Delta R_{\alpha} \\
-S_{o} \Delta A_{\text {cloud }} & \text { SW cloud feedback } \Delta R_{\text {cloud }} \\
-S_{o} \Delta A_{\text {clear,abs }} & \text { SW absorption by water vapor } \Delta R_{q}
\end{array} .\right.
$$

Atmospheric clear-sky absorption is primarily driven by changes in the absorption of incoming SW radiation by atmospheric water vapor, so this term is therefore interpreted as the SW water vapor feedback (implicit in this assumption is that the change in SW absorption due to volcanic aerosols is small relative to that due to water vapor changes). The above estimate of land-use forcing is an upper bound as it assumes that all surface albedo changes in agricultural areas are derived from land-use changes and ignores any contribution from changes in snow cover. In addition, land-use forcing is assumed to be dominated by surface albedo changes, as changes in latent and turbulent heat fluxes are unaccounted for.

Plugging Eqs. (6)-(9) into Eq. (5), we find the changes in shortwave radiation at the top of the atmosphere in terms of forcings and feedbacks:

$$
\Delta R_{\mathrm{SW}}=\underbrace{\Delta F_{\text {solar }}+\Delta F_{\text {volc }}}_{\text {SW Forcings }}+\Delta F_{\text {landuse }}+\underbrace{\Delta R_{\mathrm{SW}, \text { cloud }}+\Delta R_{\mathrm{SW}, q}+\Delta R_{\alpha}}_{\text {SW Feedback }}+\varepsilon_{\mathrm{SW}},
$$

where

$$
\varepsilon_{\mathrm{SW}}=-S_{o} \Delta A_{\text {resid }}-\Delta S \Delta A
$$

is the SW residual, which provides a measure of the accuracy of the APRP approximation to the SW TOA fluxes.

\section{2) THE LONGWAVE BudgeT}

The change in the TOA longwave radiation is

$$
\Delta R_{\mathrm{LW}}=\underbrace{\Delta F_{\mathrm{GHG}}}_{\text {LW Forcing }}+\underbrace{\Delta R_{\text {Planck }}+\Delta R_{\mathrm{LW}, \text { cloud }}+\Delta R_{\mathrm{LW}, q}+\Delta R_{\text {lapse_rate }}}_{\text {LW Feedbacks }}+\varepsilon_{\mathrm{LW}} \text {, }
$$

where $\Delta F_{\mathrm{GHG}}$ is the forcing due to the change in the concentration of greenhouse gases [calculated using the formulas from Myhre et al. (1998)]; $\Delta R_{\text {Planck }}, \Delta R_{\text {cloud }}, \Delta R_{q}$, and $\Delta R_{\text {lapse rate }}$ are the Planck, cloud, water vapor, and lapse rate feedbacks; and $\varepsilon_{\mathrm{LW}}$ is the longwave residual.

\section{3) THE TOTAL TOA ENERGY BUDGET}

Inserting Eqs. (10) and (11) into the total TOA energy budget equation [Eq. (1)], we have

$$
\Delta F+\Delta R_{\text {resp }}=\Delta R_{\text {imbal }}=\Delta R_{\mathrm{SW}}+\Delta R_{\mathrm{LW}},
$$

where $\Delta F$ is the sum of the forcings,

$$
\Delta F=\Delta F_{\text {solar }}+\Delta F_{\text {volc }}+\Delta F_{\text {landuse }}+\Delta F_{\mathrm{GHG}}
$$

$\Delta R_{\text {resp }}$ is the sum of the shortwave and longwave feedbacks, 


$$
\begin{aligned}
\Delta R_{\text {resp }}= & \underbrace{\Delta R_{\mathrm{SW}, \text { cloud }}+\Delta R_{\mathrm{SW}, q}+\Delta R_{\alpha}}_{\text {SW Feedbacks }}+\underbrace{\Delta R_{\text {Planck }}+\Delta R_{\mathrm{LW}, \text { cloud }}+\Delta R_{\mathrm{LW}, q}+\Delta R_{\text {lapse_rate }}}_{\text {LW Feedbacks }} \\
& +\varepsilon_{\mathrm{SW}}+\varepsilon_{\mathrm{LW}} ;
\end{aligned}
$$

and $\Delta R_{\text {imbal }}$ is the energy imbalance if the system is not yet in equilibrium.

Assuming the change in the global average surface air temperature $\left(\Delta \overline{T_{\text {as }}}\right)$ is small, we can expand the climate response in terms of a Taylor series:

$$
\begin{aligned}
\Delta R_{j} & =\frac{d R_{j}}{d \overline{T_{\mathrm{as}}}} \Delta \overline{T_{\mathrm{as}}}+O\left[\left(\Delta \overline{T_{\mathrm{as}}}\right)^{2}\right] \approx \frac{\partial R_{j}}{\partial x_{j}} \frac{d x_{j}}{d \overline{T_{\mathrm{as}}}} \Delta \overline{T_{\mathrm{as}}} \\
& \equiv \lambda_{j} \times \Delta \overline{T_{\mathrm{as}}},
\end{aligned}
$$

where $x_{j}$ is a state variable. The shortwave changes due to climate feedbacks are obtained by the APRP method of Taylor et al. (2007), while the longwave changes due to climate feedbacks are obtained using radiative kernels (Soden and Held 2006). Note that cloud feedbacks cannot be calculated directly from radiative kernels because of strong nonlinearities that arise from cloud masking. Following Soden et al. (2008), we adjusted the cloud radiative effect by correcting for noncloud feedbacks (where the clear-sky GHG forcing was calculated as $\Delta F_{\mathrm{GHG}}^{\mathrm{CS}}=1.16 \Delta F_{\mathrm{GHG}}$ ).

\section{4) Contributions to the CHANGe in SURFACE AIR TEMPERATURE}

Inserting Eq. (15) into Eq. (12), we find the temperature response in terms of the forcings and feedbacks [as in Feldl and Roe (2013) and Vial et al. (2013)]:

$$
\begin{aligned}
& \lambda_{\text {Planck }} \Delta \overline{T_{\text {as }}}+\sum_{j \neq \text { Planck }} \lambda_{j} \times \Delta \overline{T_{\text {as }}} \\
& =-\Delta F+\Delta R_{\text {imbal }}-\varepsilon_{\mathrm{SW}}-\varepsilon_{\mathrm{LW}},
\end{aligned}
$$

where $\lambda_{\text {Planck }}$ defines the climate sensitivity in absence of feedbacks. Equivalently,

$$
\begin{aligned}
\Delta \overline{T_{\text {as }}}= & -\Delta F / \lambda_{\text {Planck }}-\sum_{j \neq \text { Planck }} \lambda_{j} / \lambda_{\text {Planck }} \times \Delta \overline{T_{\text {as }}} \\
& +\Delta R_{\text {imbal }} / \lambda_{\text {Planck }}-\left(\varepsilon_{\text {SW }}+\varepsilon_{\mathrm{LW}}\right) / \lambda_{\text {Planck }},
\end{aligned}
$$

where $\lambda_{j}$ are the climate feedback factors (in $\left.\mathrm{W} \mathrm{m}^{-2} \mathrm{~K}^{-1}\right)$.

Finally, we can equate each term in Eq. (17) as a contribution to the global average temperature change, $\Delta \overline{T_{\mathrm{as}}}$ :

$$
\Delta \bar{T}_{\text {as }}=\Delta \bar{T}_{\text {forcing }}+\Delta \bar{T}_{\text {feedbacks }}+\Delta \bar{T}_{\text {atm+ocean_uptake }}+\Delta \bar{T}_{\varepsilon} .
$$

In addition to the forcing and feedbacks, we report the fraction $f$ of the total global cooling $\Delta \overline{T_{\text {as }}}$ due to individual forcings and feedbacks:

$$
f=\frac{\Delta \overline{T_{x}}}{\sum \Delta \overline{T_{x}}} \times 100 .
$$

Only negative (cooling) $\Delta \overline{T_{x}}$ were included in calculating $f$. There are two major assumptions underlying the global cooling contributions presented here: 1 ) the climate feedbacks include only the first-order terms of the Taylor series expansion of global mean surface temperature change (while higher-order terms are incorporated into the residual) and 2) the feedback factors associated with the different forcing agents are assumed to be equal. While the nonlinear feedback terms are typically assumed to be small and neglected (e.g., Soden and Held 2006), it has been shown that the feedback strength can vary with the type of forcing. This point is addressed in section $3 b$.

\section{Results and discussion}

\section{a. Temperature trends over the last millennium in the CMIP5-PMIP3 models}

The globally averaged surface temperature anomaly through the last millennium and preindustrial control simulations is shown in Fig. 2c (where annually averaged data were smoothed with a Gaussian filter; $\sigma=3 \mathrm{yr}$ ). Relative to the period from 850-1200 CE, all CMIP5PMIP3 simulations generally demonstrate colder global temperatures circa 1250-1850 CE. Compared to the preindustrial control simulations from the same models, the last millennium simulations demonstrate global temperature anomalies outside the range of natural variability during volcanically active periods circa $1230-1300,1450$, 1600-1750, and 1800-1840 CE. Average NH temperature anomalies in the multimodel mean agree well with proxy-derived $\mathrm{NH}$ temperature reconstructions, with long-term (centennial scale) cooling of several tenths of a degree Celsius through the last millennium and pronounced cold periods through the thirteenth, midfifteenth, seventeenth and eighteenth, and early nineteenth centuries (Fig. 3; Frank et al. 2010). Temperature anomalies associated with large volcanic events tend to be substantially larger in the models than in the reconstructions. This issue has been well 


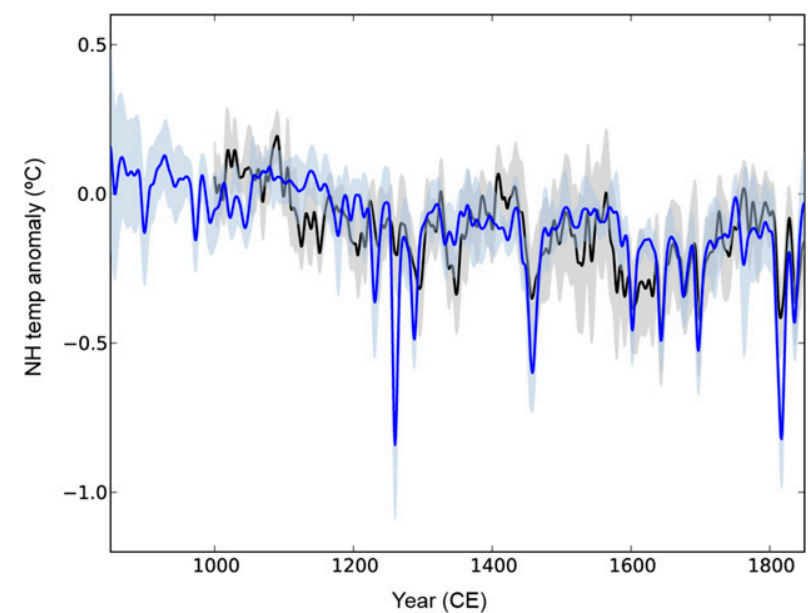

FIG. 3. Mean NH temperature anomaly from the CMIP5-PMIP3 last millennium simulations (blue) and from 521 proxy-based ensemble estimates [black; Frank et al. (2010)] based on nine different large-scale $\mathrm{NH}$ temperature reconstructions spanning the last millennium. Temperature anomalies are calculated relative to the MCA (950-1200 CE) and annually averaged data were smoothed with a Gaussian filter with $\sigma=3 \mathrm{yr}$. Solid lines represent the multimodelmultireconstruction mean and shading represents $\pm 1 \sigma$.

documented and may be due to errors in the tree-ringbased temperature reconstructions [e.g., anomalous tree growth immediately following large volcanic events; Mann et al. (2012)], to uncertainties in the volcanic reconstructions (Sigl et al. 2014), and/or to the models' tendency to overestimate the impact of large volcanic events (e.g., because of the linear scaling based on the Mount Pinatubo eruption that is typically applied between stratospheric sulfate loading and AOD) (Timmreck et al. 2009).

To quantify the contribution of radiative forcings and climate feedbacks to global cooling over the last millennium, we compare the energy budget in the LIA (hereafter defined as $1600-1850 \mathrm{CE}$ ) to that in the MCA (950-1200 CE). We extend our analysis to examine the cause of the cold periods circa 1400-1650 and 1200-1450 CE (relative to the same MCA warm period) in section $3 \mathrm{~d}$.

While the LIA is characterized by centennial-scale global temperature minima in all CMIP5-PMIP3 models, there are marked differences in the amplitude and spatial pattern of the surface temperature anomalies (relative to the MCA) across the models (Fig. 4). The regional temperature differences are reflected in changes in sea ice concentration (Fig. 5); in the Arctic, sea ice concentration increases in all models, whereas Antarctic sea ice concentration increases in some models (CCSM4, CSIRO, and HadCM3) and decreases in others (GISS 121 and GISS 124). Sources of these intermodel differences are discussed in section $3 \mathrm{c}$.

\section{b. Attribution of LIA cooling}

Climate forcing during the last millennium is composed of contributions from changes in solar output, orbital configuration, stratospheric sulfate aerosols associated with large volcanic eruptions, changes in trace gases, and changes in land use (Table 1; Bony et al. 2006; Schmidt et al. 2011). The forcings are shown in Fig. 6 and the global cooling contribution from each of these forcings is shown in Fig. 7 and Table 2.

A TOA energy budget analysis of the CMIP5-PMIP3 last millennium simulations indicates that volcanic forcing was the primary driver of LIA cooling in the models. Volcanic forcing accounted for $65 \%$ of the total forcing on average (ranging from $50 \%$ to $73 \%$ or -0.07 to $-0.32 \mathrm{~W} \mathrm{~m}^{-2}$, across models; Fig. 6). This forcing directly contributed to $31 \%$ (on average) of the global cooling during the LIA (Fig. 7; Table 2). In comparison, land use, GHG, and solar forcing were substantially weaker, accounting for an average of $13 \%, 12 \%$, and $10 \%$ of the total forcing and $7 \%, 5 \%$, and $4 \%$ of the global cooling, respectively. Globally averaged solar forcing was driven by changes in solar output over the last millennium as changes in orbital parameters imparted insignificant forcing (Fig. 6). However, it is important to note that the insignificance of the direct orbital forcing term when globally and annual averaged does not necessarily imply that orbital forcing played an insignificant role in global cooling during the LIA. Orbital forcing (which has a rich seasonal and latitudinal structure) likely triggered global climate feedbacks. For instance, precessional forcing imposed a $\sim 3 \mathrm{~W} \mathrm{~m}^{-2}$ decrease in insolation in boreal summer (JJA) at $65^{\circ} \mathrm{N}$ through the last millennium (Fig. 2e), which may have contributed to nonnegligible surface albedo and water vapor feedbacks through colder temperatures and sea ice growth in the Arctic.

A number of positive climate feedbacks reinforce the radiative forcing during the LIA. The global cooling contribution from each of these feedbacks is shown in Fig. 7, while the global energy fluxes are shown in the supplemental material (see Fig. S1). (Feedbacks and global cooling contributions were not calculated for the HadCM3 and CSIRO last millennium simulations because relative humidity data were not available for HadCM3 and the implementation of volcanic forcing as a TSI perturbation in CSIRO precluded separation of the SW forcings and feedbacks.) Under the current analysis framework, these feedbacks cannot be ascribed to any particular type of forcing and thus we assume that the strength of the feedbacks is independent of the forcing agent. Although it has been pointed out that the feedback strength can vary with the type of forcing, 

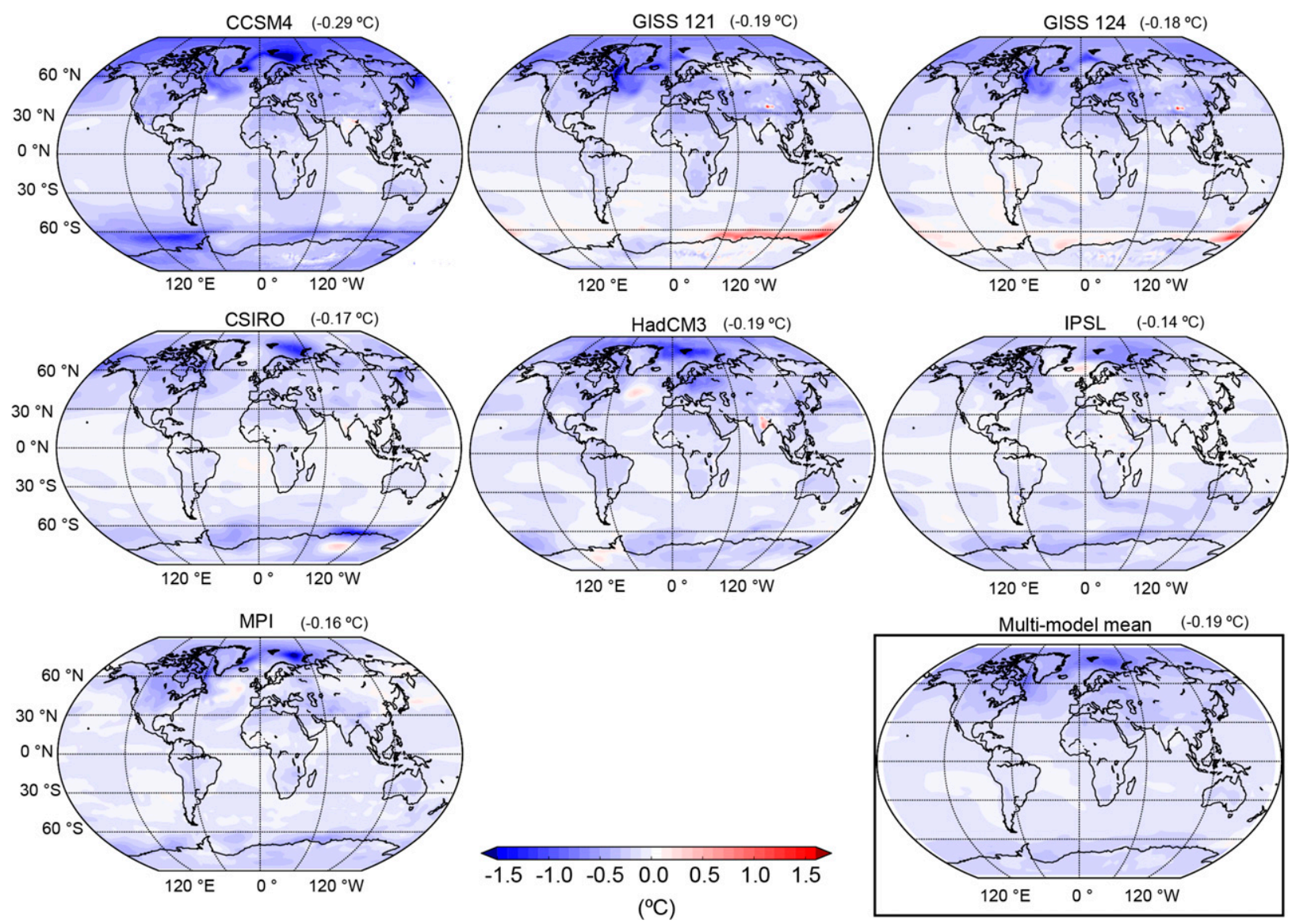

FIG. 4. LIA (1600-1850 CE) minus MCA (950-1200 CE) surface air temperature changes in the CMIP5-PMIP3 simulations. The value in parentheses next to each model name represents the global mean surface temperature change.

the differences appear to be small among solar, greenhouse gas, and volcanic forcings (Hansen et al. 2005). This, combined with the result that volcanic forcing dominates the forcing during the LIA, suggests that this source of uncertainty in the LIA cooling contributions is likely to be small. Another important point regarding the inability to distinguish between feedbacks associated with different forcing mechanisms is that we are unable to quantify the total (direct and indirect) cooling associated with the individual forcing mechanisms; it is therefore possible that forcings that had negligible direct contributions to LIA cooling (e.g., orbital forcing) may have been responsible for nonnegligible climate feedbacks.

The largest positive feedback is the LW water vapor feedback, which is responsible for $20 \%$, on average, of the global cooling (Table 2). The LW water vapor feedback occurs in response to the decreased atmospheric water vapor concentration; the saturation vapor pressure decreases as the atmosphere cools, as given by the Clausius-Clapeyron equation. In addition, the SW water vapor feedback represents a lesser but globally important positive feedback in all of the models (contributing $9 \%$, on average, to the global cooling), consistent with decreased absorption of incoming SW radiation by atmospheric water vapor during the LIA.

In global warming simulations, the positive water vapor feedback is due to both the vertically uniform atmospheric warming as well as the vertical redistribution of water vapor (as robust decreases in tropical lapse rate from enhanced warming aloft lead to an upward shift in the water vapor distribution). In the CMIP5 $4 \times \mathrm{CO}_{2}$ simulations, the large positive water vapor feedback is partially offset by a negative lapse rate feedback. In contrast, the CMIP5-PMIP3 last millennium simulations demonstrate water vapor and lapse rate feedbacks that reinforce one another. The positive lapse rate feedback arises as a result of greater cooling near the surface than aloft poleward of $\sim 30^{\circ}-40^{\circ}$ latitude (Fig. S2 in the supplemental material) and contributes $7 \%$ on average to the global cooling (Fig. 7; Table 2). A positive lapse rate feedback has also been observed in Last Glacial 

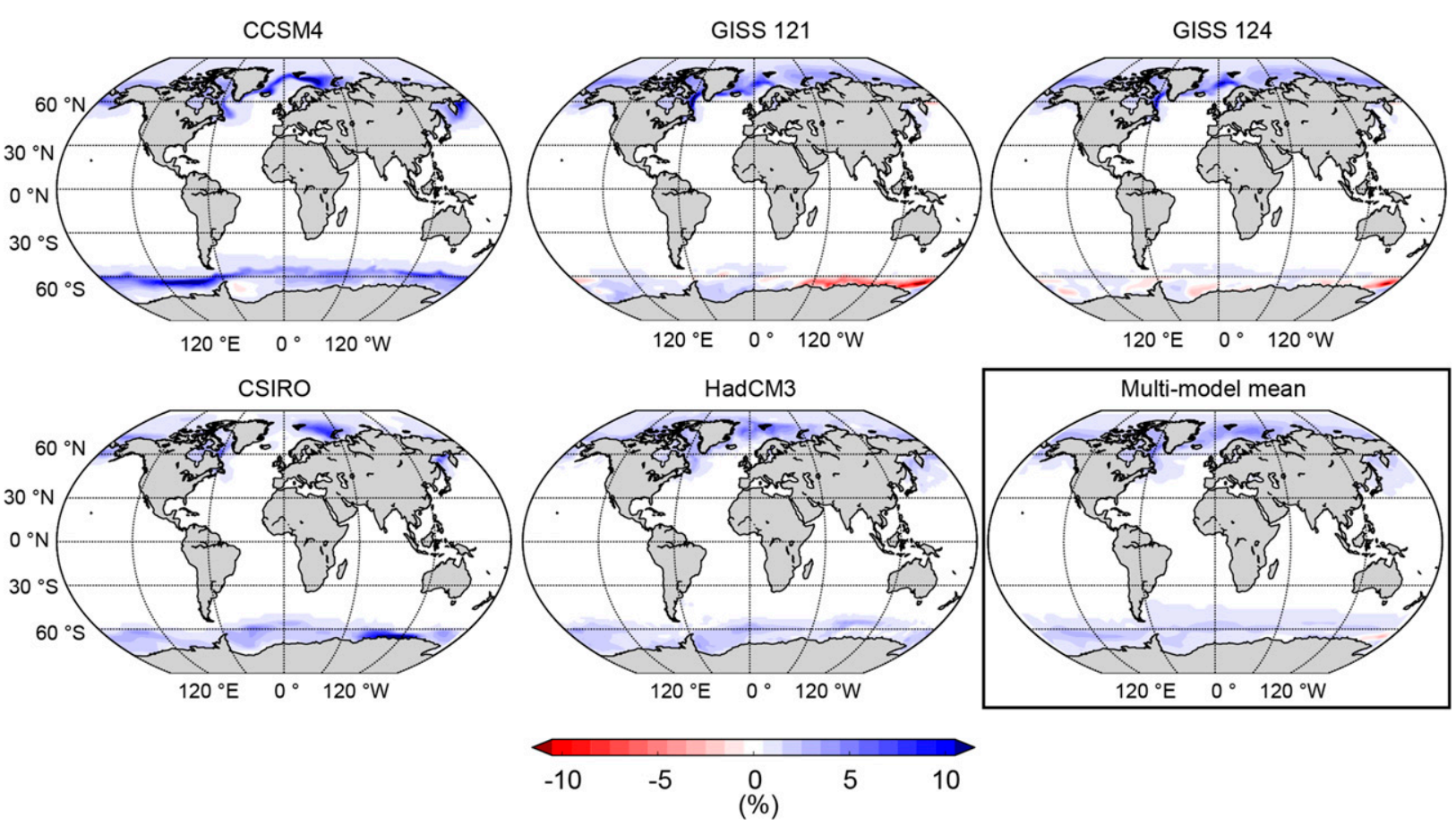

10

FIG. 5. As in Fig.4, but for sea ice concentration. Sea ice data were not available for IPSL.

Maximum simulations with a slab-ocean model under the addition of ice sheet and orbital forcings (Yoshimori et al. 2011), suggesting that the positive (versus negative) lapse rate feedback may be a function of the SW (versus LW) forcings. In the last millennium simulations, the largest lapse rate changes occur poleward of around $40^{\circ} \mathrm{N}$ (Fig. S2) and likely involve a combination of land-use forcing and increased high-latitude snow cover and sea ice. Combined, the water vapor and lapse rate feedbacks are responsible for $36 \%$, on average, of the global cooling during the LIA. Thus, while the total (SW + LW) water vapor feedback $\left(1.20 \pm 0.19 \mathrm{~W} \mathrm{~m}^{-2} \mathrm{~K}^{-1}\right.$; Fig. 8$)$ is substantially less than that reported from the CMIP5 $4 \times$ $\mathrm{CO}_{2}$ simulations, the combined water vapor and lapse rate feedback in the LIA (relative to the MCA; $1.47 \pm$ $0.10 \mathrm{~W} \mathrm{~m}^{-2} \mathrm{~K}^{-1}$ ) is larger than that observed in the future climate simulations $\left(1.26 \pm 0.07 \mathrm{~W} \mathrm{~m}^{-2} \mathrm{~K}^{-1}\right.$; MassonDelmotte et al. 2013). The combined LIA water vapor and lapse rate feedback is closer to that observed in Last Glacial Maximum simulations compared to the preindustrial climate $\left(1.39 \pm 0.09 \mathrm{~W} \mathrm{~m}^{-2} \mathrm{~K}^{-1}\right.$; Masson-Delmotte et al. 2013). likely due in part to the nonlinearity associated with the Clausius-Clapeyron relation, and in part to differences in the vertical profile of atmospheric temperature changes.

Second to the water vapor feedback, the next largest SW feedback is the surface albedo feedback $(0.23 \pm$ $0.20 \mathrm{~W} \mathrm{~m}^{-2} \mathrm{~K}^{-1}$ ), which is responsible for $7 \%$ of the global cooling on average (Fig. 7; Table 2). The surface albedo feedback arises primarily from increases in highlatitude sea ice as well as from increased snow cover in parts of Eurasia and North America. This surface albedo feedback is generally similar to that found from the CMIP5 $4 \times \mathrm{CO}_{2}$ simulations $\left(0.33 \pm 0.14 \mathrm{~W} \mathrm{~m}^{-2} \mathrm{~K}^{-1}\right.$; Masson-Delmotte et al. 2013) and the PMIP3 Last Glacial Maximum simulations $\left(0.41 \pm 0.18 \mathrm{~W} \mathrm{~m}^{-2} \mathrm{~K}^{-1}\right.$; Masson-Delmotte et al. 2013).

Not unexpectedly, clouds have a varied response among models, most notably in the SW cloud feedback. The LW cloud feedback $\left(0.27 \pm 0.17 \mathrm{~W} \mathrm{~m}^{-2} \mathrm{~K}^{-1}\right)$ is positive in all models and is broadly consistent with that found in the CMIP5 $4 \times \mathrm{CO}_{2}$ simulations $(0.22 \pm$ $0.18 \mathrm{~W} \mathrm{~m}^{-2} \mathrm{~K}^{-1}$; Masson-Delmotte et al. 2013) and, generally, is higher than that found in the Last Glacial Maximum simulations $\left(0.08 \pm 0.10 \mathrm{~W} \mathrm{~m}^{-2} \mathrm{~K}^{-1}\right.$; Masson-Delmotte et al. 2013). The positive LW cloud feedback is likely due to lower cloud tops in the colder LIA atmosphere. The LW cloud feedback contributes $8 \%$, on average, to the global cooling. The SW cloud feedback $\left(-0.20 \pm 0.47 \mathrm{~W} \mathrm{~m}^{-2} \mathrm{~K}^{-1}\right)$ is more variable among the models, which is a well-documented feature across future and paleoclimate simulations (e.g., MassonDelmotte et al. 2013; Vial et al. 2013). In all last millennium simulations aside from IPSL, the SW cloud feedback is a negative feedback during the LIA and generally arises from decreased cloud fractions in the 
A)

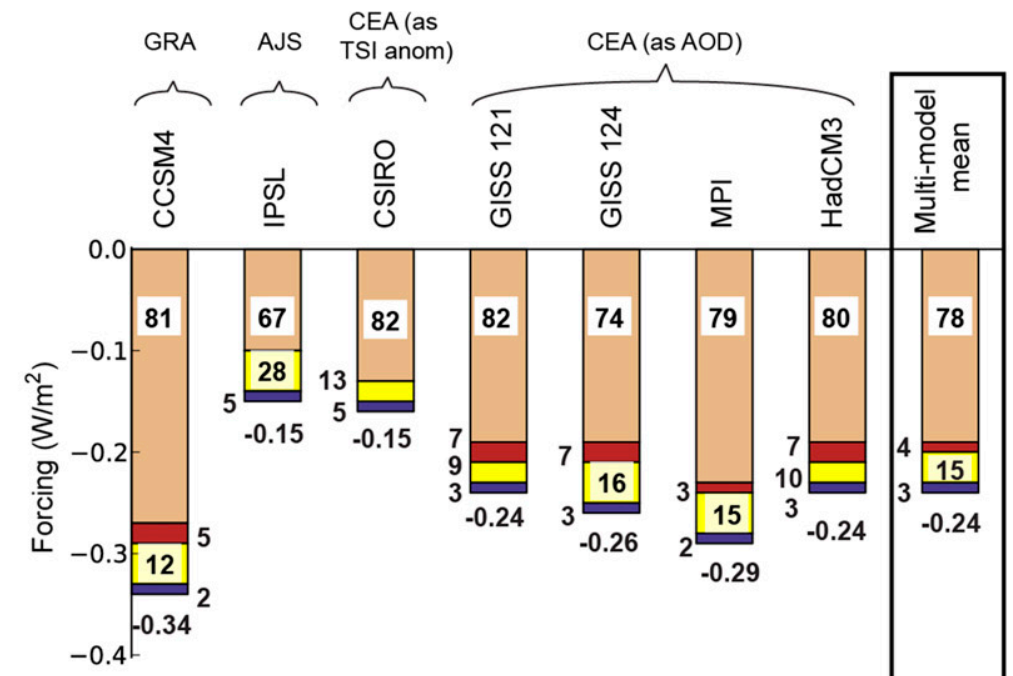

B)

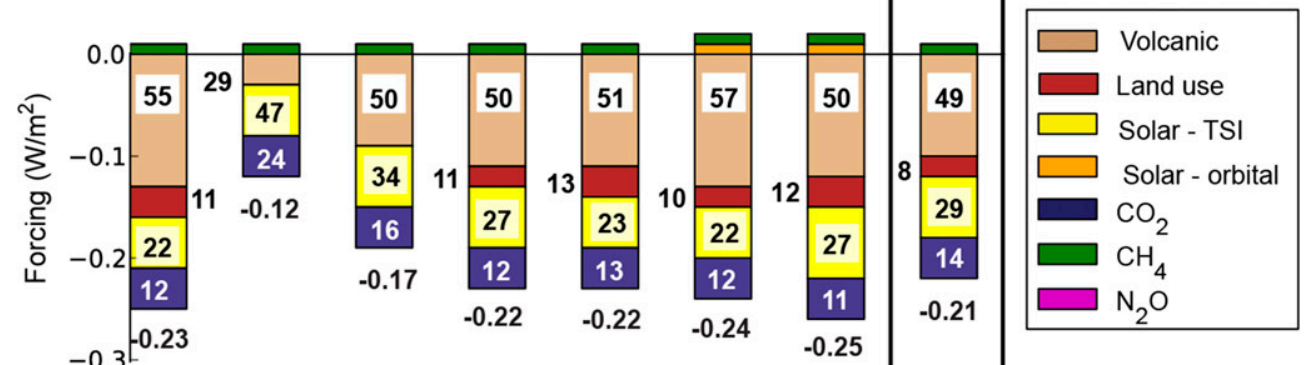

C)

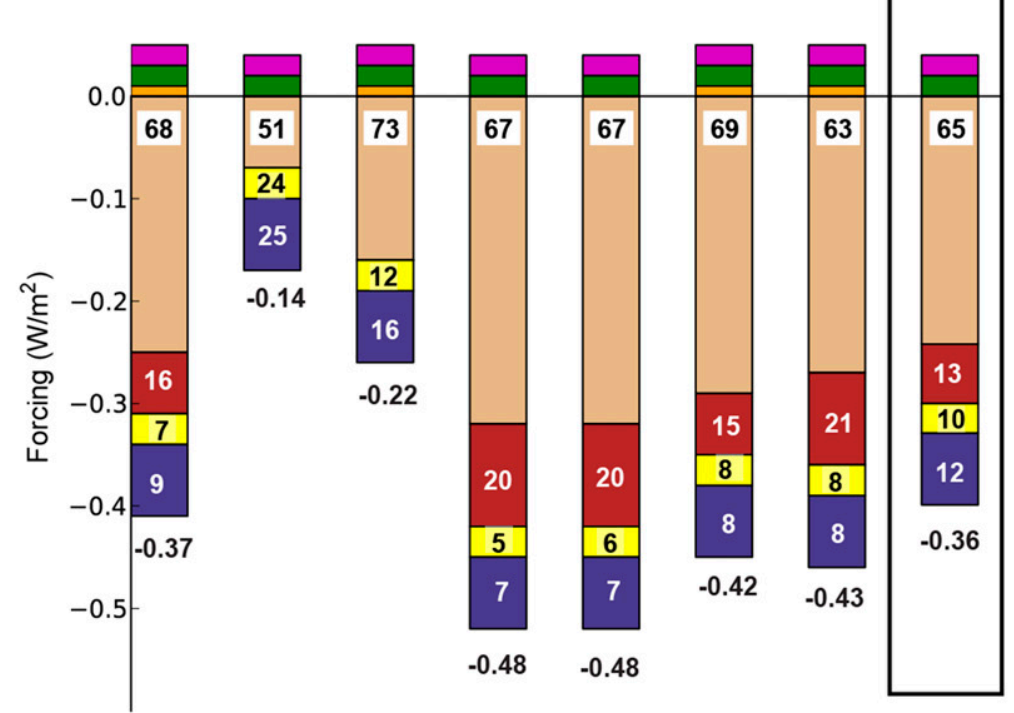

FIG. 6. Decomposition of radiative forcings in the CMIP5-PMIP3 last millennium simulations into contributions from volcanic aerosols, solar output, orbital configuration, and the well-mixed GHGs for period from (a) 1200-1450, (b) 1400-1650, and (c) 1600-1850 CE, relative to the MCA (950-1200 CE). Percentages in the brown, yellow, and blue boxes represent fractional contributions to total forcing from volcanic, land use, TSI, and total $\mathrm{GHG}\left(\mathrm{CO}_{2}, \mathrm{CH}_{4}\right.$, and $\left.\mathrm{N}_{2} \mathrm{O}\right)$ forcings, respectively. Values below the bars represent total forcing $\left(\mathrm{W} \mathrm{m}^{-2}\right)$. GRA, AJS, and CEA (at the top of the figure) indicate the volcanic forcing dataset used [see section 2a(1)]. 


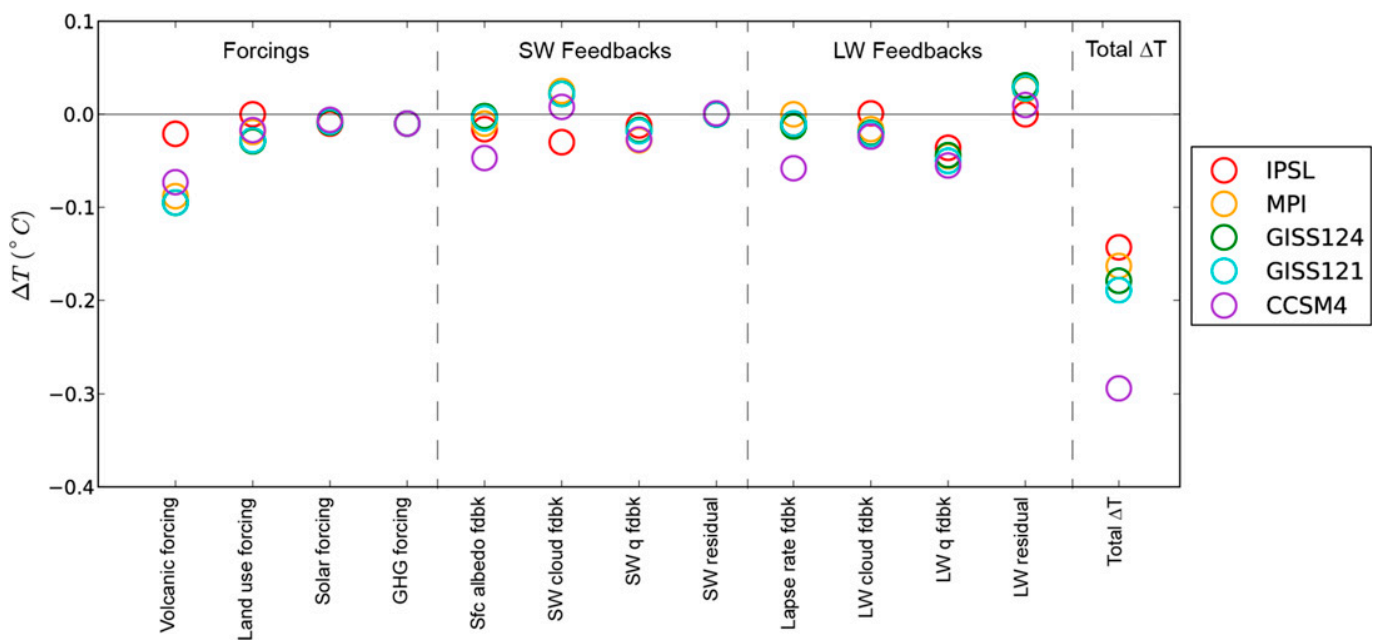

FIG. 7. Global cooling contributions from Eq. (18) due to volcanic, land use, solar, and GHG forcings and the SW and LW feedbacks compared to the total globally averaged temperature change between the LIA (1600-1850 CE) and MCA (950-1200 CE). The difference between the total cooling and the sum of the forcings and feedbacks is the Planck response. Global cooling contributions were not calculated for HadCM3 and CSIRO because of data unavailability (see text for details).

tropics and high latitudes. The positive SW cloud feedback in IPSL is the dominant positive feedback and arises from increased cloud fractions in the midlatitudes, particularly in the SH (data not shown). A strong correlation between SW cloud feedback and low-cloud fidelity has been found in future climate simulations. The SW cloud feedback is strongly positively correlated to the SW cloud radiative effect present in the control simulation, with a larger positive SW cloud feedback present in models with higher control over low cloud cover (Lacagnina et al. 2014). This relationship suggests that the large intermodel spread in the SW cloud feedback may be indicative of a large intermodel spread in low cloud amount in the last millennium control simulations.

Combined, these feedbacks are responsible for an average of $53 \%$ of the global cooling during the LIA. The water vapor, lapse rate, surface albedo, and cloud feedback parameters sum to $1.85 \pm 0.54 \mathrm{~W} \mathrm{~m}^{-2} \mathrm{~K}^{-1}$, similar to the combined feedback parameter from the Last Glacial Maximum simulations $\left(1.87 \pm 0.21 \mathrm{~W} \mathrm{~m}^{-2} \mathrm{~K}^{-1}\right)$ and the $4 \times \mathrm{CO}_{2}$ simulations $\left(2.19 \pm 0.35 \mathrm{~W} \mathrm{~m}^{-2} \mathrm{~K}^{-1}\right.$; Masson-Delmotte et al. 2013). The larger combined water vapor and lapse rate feedback in the LIA, relative to the future climate simulations, is more than offset by the lower average SW cloud feedback. It has similarly been demonstrated that the lower climate feedback parameter in the Last Glacial Maximum relative to future climate simulations is primarily due to a lower SW cloud feedback (Yoshimori et al. 2011; Masson-Delmotte et al. 2013).
Finally, we note that the SW residual term is negligible (less than $0.01 \mathrm{~W} \mathrm{~m}^{-2} \mathrm{~K}^{-1}$ ) while the $\mathrm{LW}$ residual term ranges from 0.00 to $-0.59 \mathrm{~W} \mathrm{~m}^{-2} \mathrm{~K}^{-1}$, or $0 \%-31 \%$ of the total LW feedback parameter (Fig. S1). This residual indicates the presence of nonlinear LW feedbacks, while LW absorption by volcanic aerosols (which has been neglected in this analysis) may also contribute to the residual. The average total residual $(20 \%)$ is similar to that reported from the CMIP5 $4 \times \mathrm{CO}_{2}$ simulations [23\%; Vial et al. (2013)].

\section{c. Sources of intermodel differences in LIA climate change}

While the LIA is characterized by global cooling relative to the MCA in all models, the amplitude of the cooling differs by more than a factor of 2 among the models (Fig. 7). Factors that may be responsible for the intermodel spread in global mean temperature change include differing climate forcings, differing climate feedbacks, and differing efficiencies with which they transfer heat into the ocean. However, as ocean heat uptake during the LIA is small in all the models (as demonstrated by small changes in surface energy fluxes in Fig. S1), the TOA radiative forcings and feedbacks are primarily responsible for the intermodel spread in global cooling during the LIA. Among radiative forcings, differences in volcanic forcing dominate the intermodel spread in total forcing, while the presence or absence of land-use forcing also contributes to the spread (Fig. 6). Differences in volcanic forcing across models could arise from differences in the forcing 


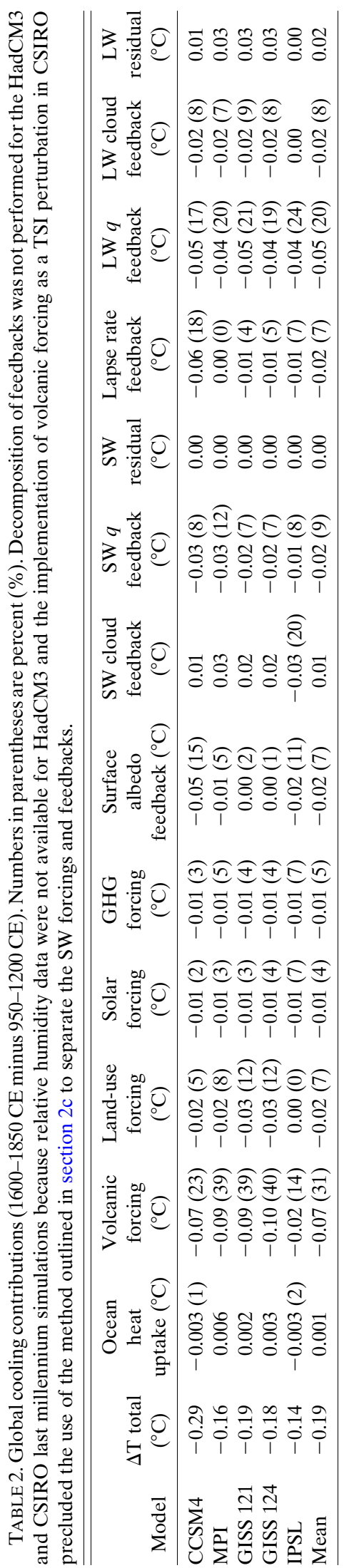

dataset used (therefore reflecting uncertainty in the volcanic aerosol reconstructions) as well as from differences in the treatment of volcanic aerosols in the models. The differing treatment of volcanic aerosols appears to be responsible for a substantial portion of the intermodel spread in volcanic forcing. For instance, volcanic forcing in CSIRO (which was prescribed as a globally averaged perturbation to TSI based on the CEA dataset) is up to $50 \%$ lower than that in GISSMPI-HadCM3 (which prescribed AOD and effective radius from CEA as a function of height and latitude in the stratosphere; Fig. 6). The use of different forcing datasets is also likely responsible for some of the intermodel spread in volcanic forcing during the LIA. CCSM4 has an atmospheric chemistry scheme that models the radiative properties of the volcanic aerosols from the aerosol loading provided in GRA. The LIA forcing in CCSM4 varies from $20 \%$ lower to $40 \%$ greater (depending on the LIA period chosen) than the mean of the four models that prescribed AOD from CEA. The weak volcanic forcing in IPSL is likely in part related to the daily drift of the aerosol extinction coefficient (see section 2).

In addition to differences in radiative forcing among models, differences in the strength of climate feedbacks add to the intermodel spread in LIA cooling. The total effective feedback parameter differs by a factor of 2 across models (ranging from -0.97 to $-1.99 \mathrm{~W} \mathrm{~m}^{-2} \mathrm{~K}^{-1}$; Fig. 8). The Planck response varies little among models, as expected $\left(-3.41 \pm 0.05 \mathrm{Wm}^{-2} \mathrm{~K}^{-1}\right)$. The largest spread in climate feedbacks among models occurs in the SW cloud feedback $\left(-0.20 \pm 0.47 \mathrm{~W} \mathrm{~m}^{-2} \mathrm{~K}^{-1}\right)$, the lapse rate feedback $\left(0.27 \pm 0.25 \mathrm{~W} \mathrm{~m}^{-2} \mathrm{~K}^{-1}\right)$, and the surface albedo feedback $\left(0.23 \pm 0.20 \mathrm{~W} \mathrm{~m}^{-2} \mathrm{~K}^{-1}\right)$. The large spread in the SW cloud feedback is a common feature in GCM simulations (Crucifix 2006; Soden and Held 2006; Vial et al. 2013). The large spread in the surface albedo and lapse rate feedbacks is likely in part due to the varied response of high-latitude sea ice among models (Fig. 5; Fig. S2).

\section{d. Sensitivity of results to definition of LIA}

The processes (forcings and feedbacks) that are responsible for the cold conditions during the periods 1200-1450 and 1400-1650 CE are qualitatively similar to those responsible for the cold conditions in the LIA (i.e., from 1600 to $1850 \mathrm{CE}$ ). During all three periods, volcanic forcing is the dominant forcing, with multimodel means of $78 \%, 49 \%$, and $65 \%$ of the total forcing during the 1200-1450, 1400-1650, and 1600-1850 CE periods, respectively (Fig. 6). The 1600-1850 CE period is characterized by the largest total forcing $\left(-0.36 \mathrm{~W} \mathrm{~m}^{-2}\right.$ in the multimodel mean). In contrast, the 1400-1650 CE period has the weakest total forcing 


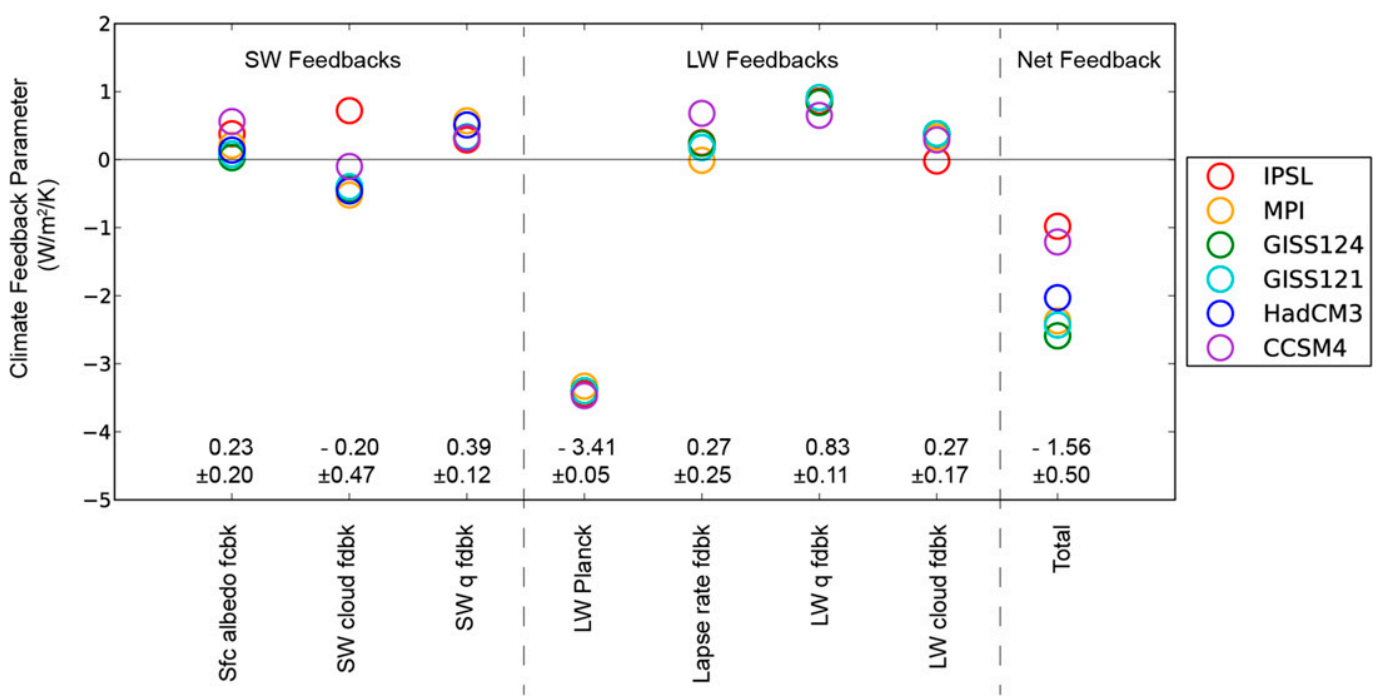

FIG. 8. LIA climate feedback parameters calculated from the CMIP5-PMIP3 simulations for the SW feedbacks (surface albedo, SW cloud, and SW $q$ ), the LW feedbacks (Planck response, lapse rate, LW $q$, and LW cloud), and the sum of the feedbacks. Decomposition of feedbacks was not performed for HadCM3 and CSIRO because of data unavailability (see text for details).

$\left(-0.21 \mathrm{~W} \mathrm{~m}^{-2}\right)$, but it features the strongest relative contribution from solar forcing $(29 \%)$, as it contains the Spörer minimum. Contributions from land use and greenhouse gas forcings are larger in 1600-1850 CE (13\% and $12 \%$ respectively) and in 1400-1650 CE ( $8 \%$ and $14 \%$, respectively) as compared to $1200-1450 \mathrm{CE}$ (4\% and $3 \%$, respectively).

In addition to substantial differences in total forcing across the three cold epochs, there are substantial differences in the effective climate feedback parameter across the epochs (ranging from -0.97 to $-1.99 \mathrm{~W} \mathrm{~m}^{-2} \mathrm{~K}^{-1}$ ). Differences in the feedback parameter arise primarily because of differences in the SW cloud feedback, lapse rate feedback, and surface albedo feedback. Ocean heat uptake is small across all three periods, as demonstrated by changes in global mean surface energy fluxes of less than $\pm 0.05 \mathrm{~W} \mathrm{~m}^{-2} \mathrm{~K}^{-1}$ (Fig. S1).

\section{Conclusions}

The CMIP5-PMIP3 last millennium simulations feature extended periods of cold conditions across the globe during the period circa 1200-1850 CE. Temperature anomalies averaged over the $\mathrm{NH}$ during this time generally agree well with proxy-based temperature reconstructions. Analysis of the global TOA energy budget during the last millennium using APRP and radiative kernel techniques indicates that volcanic forcing is primarily responsible for the cold conditions in the CMIP5-PMIP3 models. Volcanic forcing contributes averages of $78 \%, 49 \%$, and $65 \%$ of the total forcing in the multimodel mean for the cold epochs in 1200-1450, 1400-1650, and 1600-1850 CE, respectively. Forcing contributions due to changes in insolation $(15 \%, 29 \%$, and $10 \%)$, land use $(4 \%, 8 \%$, and $13 \%)$, and greenhouse gas concentrations $(3 \%, 14 \%$, and $12 \%)$ are substantially smaller than the volcanic forcing.

A feedback analysis of the 1600-1850 CE period demonstrates that the dominant climate feedbacks that reinforce the global cooling include the water vapor and lapse rate feedbacks, which combined are responsible for $36 \%$ of the LIA cooling in the models; the positive LW and SW water vapor feedbacks are a consequence of the decrease in water vapor concentration associated with the vertically integrated cooling while the positive lapse rate feedback arises because of greater cooling near the surface than aloft poleward of $\sim 30^{\circ}-40^{\circ}$ latitude. While lapse rate changes provide a negative feedback in $4 \times \mathrm{CO}_{2}$ simulations, a positive lapse rate feedback has been observed in Last Glacial Maximum simulations. The combined water vapor and lapse rate feedback during the LIA is thus similar to that from Last Glacial Maximum simulations and larger than that from future climate simulations. Additional positive feedbacks include the surface albedo feedback, which is responsible for $7 \%$ of the global cooling on average and arises from sea ice growth and increased snow cover during the LIA, and the LW cloud feedback, which provides an additional $8 \%$ of the global cooling and is consistent with lower cloud tops in the colder LIA atmosphere.

There are several points to consider when interpreting the results of the CMIP5-PMIP3 last millennium 
simulations in light of the paleoclimate record. First, large uncertainties exist in the characterization of volcanic forcing that may not be adequately represented in the last millennium simulations. Sources of uncertainty include the reconstructions of aerosol loading, AOD, and aerosol effective radius as a function of time, latitude, and height in the atmosphere (e.g., Timmreck et al. 2009), all of which exert important controls on the climate system. A new reconstruction of volcanic aerosol loading based on a more extensive array of Antarctic ice core records found a substantially different history of volcanic aerosol deposition prior to $1500 \mathrm{CE}$ as compared to prior reconstructions (Sigl et al. 2014). These uncertainties are further compounded by the CMIP5 models' poor representation of the dynamical response of the atmosphere to volcanic eruptions (Driscoll et al. 2012). Large uncertainties also exist in the reconstructions of changes in insolation over the last millennium. One reconstruction suggests that changes in insolation during the LIA may have been an order of magnitude larger than those prescribed in the CMIP5-PMIP3 last millennium simulations (Schmidt et al. 2012; Shapiro et al. 2011). This uncertainty, in conjunction with the fact that only one of the CMIP5-PMIP3 last millennium runs included solar-driven ozone variations (Shindell et al. 2006), leaves open the possibility that solar forcing may have played a larger role in LIA cooling than is suggested by these model simulations.

Acknowledgments. This material is based upon work supported by the National Science Foundation Graduate Research Fellowship Program (DGE-1256082) and the Department of Energy Global Change Education Program (under fellowships to AA). EW and DMWF are supported by NSF Awards AGS-0846641, AGS-0936059, and AGS1359464. We thank K. Shell for providing the CAM3 radiative kernels and A. Donohoe, M. Zelinka, A. Pendergrass, K. Shell, C. Bitz, B. Santer, M. Khodri, and J.-L. Dufresne for useful discussions that improved this manuscript.

\section{REFERENCES}

Ammann, C. M., F. Joos, D. S. Schimel, B. L. Otto-Bliesner, and R. A. Tomas, 2007: Solar influence on climate during the past millennium: Results from transient simulations with the ncar climate system model. Proc. Natl. Acad. Sci. USA, 104, 37133718, doi:10.1073/pnas.0605064103.

Bard, E., G. Raisbeck, F. Yiou, and J. Jouzel, 2000: Solar irradiance during the last 1200 years based on cosmogenic nuclides. Tellus, 52B, 985-992, doi:10.1034/j.1600-0889.2000.d01-7.x.

Berger, A. L., 1978: Long-term variations of daily insolation and quaternary climatic changes. J. Atmos. Sci., 35, 2362-2367, doi:10.1175/1520-0469(1978)035<2362:LTVODI > 2.0.CO;2.

Bianchi, G. G., and I. N. McCave, 1999: Holocene periodicity in North Atlantic climate and deep-ocean flow south of Iceland. Nature, 397, 515-517, doi:10.1038/17362.
Bond, G., and Coauthors, 2001: Persistent solar influence on North Atlantic climate during the Holocene. Science, 294, 21302136, doi:10.1126/science.1065680.

Bony, S., and Coauthors, 2006: How well do we understand and evaluate climate change feedback processes? J. Climate, 19, 3445-3482, doi:10.1175/JCLI3819.1.

Braconnot, P., S. P. Harrison, M. Kageyama, P. J. Bartlein, V. Masson-Delmotte, A. Abe-Ouchi, B. Otto-Bliesner, and Y. Zhao, 2012: Evaluation of climate models using palaeoclimatic data. Nat. Climate Change, 2, 417-424, doi:10.1038/ nclimate1456.

Briffa, K. R., P. D. Jones, F. H. Schweingruber, and T. J. Osborn, 1998: Influence of volcanic eruptions on Northern Hemisphere summer temperature over the past 600 years. Nature, 393, 450455, doi:10.1038/30943.

Collins, M., S. F. B. Tett, and C. Cooper, 2001: The internal climate variability of HadCM3, a version of the Hadley Centre coupled model without flux adjustments. Climate Dyn., 17, 61-81, doi:10.1007/s003820000094.

Crowley, T. J., 2000: Causes of climate change over the past 1000 years. Science, 289, 270-277, doi:10.1126/science.289.5477.270.

_ , G. Zielinski, B. Vinther, R. Udisti, K. Kreutz, J. Cole-Dai, and E. Castellano, 2008: Volcanism and the Little Ice Age. PAGES Newsletter, Vol. 16, No. 2, PAGES International Project Office, Bern, Switzerland, 22-23.

Crucifix, M., 2006: Does the Last Glacial Maximum constrain climate sensitivity? Geophys. Res. Lett., 33, L18701, doi:10.1029/ 2006 GL027137.

Cunningham, L. K., and Coauthors, 2013: Reconstructions of surface ocean conditions from the northeast Atlantic and Nordic seas during the last millennium. Holocene, 23, 921-935, doi:10.1177/0959683613479677.

Driscoll, S., A. Bozzo, L. J. Gray, A. Robock, and G. Stenchikov, 2012: Coupled Model Intercomparison Project 5 (CMIP5) simulations of climate following volcanic eruptions. J. Geophys. Res., 117, D17105, doi:10.1029/2012JD017607.

Dufresne, J. L., and Coauthors, 2013: Climate change projections using the IPSL-CM5 Earth System Model: From CMIP3 to CMIP5. Climate Dyn., 40, 2123-2165, doi:10.1007/ s00382-012-1636-1.

Feldl, N., and G. H. Roe, 2013: Four perspectives on climate feedbacks. Geophys. Res. Lett., 40, 4007-4011, doi:10.1002/ grl.50711.

Fernandez-Donado, L., and Coauthors, 2013: Large-scale temperature response to external forcing in simulations and reconstructions of the last millennium. Climate Past, 9, 393-421, doi:10.5194/cp-9-393-2013.

Flato, G., and Coauthors, 2013: Evaluation of climate models. Climate Change 2013: The Physical Science Basis, T. F. Stocker et al., Eds., Cambridge University Press, 741-866. [Available online at https://www.ipcc.ch/pdf/assessment-report/ar5/wg1/ WG1AR5_Chapter09_FINAL.pdf.]

Frank, D. C., J. Esper, C. C. Raible, U. Buentgen, V. Trouet, B. Stocker, and F. Joos, 2010: Ensemble reconstruction constraints on the global carbon cycle sensitivity to climate. $\mathrm{Na}$ ture, 463, 527-532, doi:10.1038/nature08769.

Gao, C., A. Robock, and C. Ammann, 2008: Volcanic forcing of climate over the past 1500 years: An improved ice core-based index for climate models. J. Geophys. Res., 113, D231111, doi:10.1029/2008JD010239.

Gent, P. R., and Coauthors, 2011: The Community Climate System Model version 4. J. Climate, 24, 4973-4991, doi:10.1175/ 2011JCLI4083.1. 
Gerber, S., F. Joos, P. Brugger, T. F. Stocker, M. E. Mann, S. Sitch, and M. Scholze, 2003: Constraining temperature variations over the last millennium by comparing simulated and observed atmospheric $\mathrm{CO}_{2}$. Climate Dyn., 20, 281-299, doi:10.1007/ s00382-002-0270-8.

Hansen, J., and Coauthors, 2005: Efficacy of climate forcings. J. Geophys. Res., 110, D18104, doi:10.1029/2005JD005776.

Hegerl, G. C., T. J. Crowley, S. K. Baum, K.-Y. Kim, and W. T. Hyde, 2003: Detection of volcanic, solar and greenhouse gas signals in paleo-reconstructions of Northern Hemispheric temperature. Geophys. Res. Lett., 30, 1242, doi:10.1029/ 2002GL016635.

,-- , M. Allen, W. T. Hyde, H. N. Pollack, J. Smerdon, and E. Zorita, 2007: Detection of human influence on a new, validated 1500-year temperature reconstruction. J. Climate, 20, 650-666, doi:10.1175/JCLI4011.1.

Hwang, Y. T., D. M. W. Frierson, and S. M. Kang, 2013: Anthropogenic sulfate aerosol and the southward shift of tropical precipitation in the late 20th century. Geophys. Res. Lett., 40 , 2845-2850, doi:10.1002/grl.50502.

Jones, P. D., K. R. Briffa, T. P. Barnett, and S. F. B. Tett, 1998: High-resolution palaeoclimatic records for the last millennium: Interpretation, integration and comparison with general circulation model control-run temperatures. Holocene, $\mathbf{8 , 4 5 5 -}$ 471, doi:10.1191/095968398667194956.

Joos, F., and R. Spahni, 2008: Rates of change in natural and anthropogenic radiative forcing over the past 20,000 years. Proc. Natl. Acad. Sci. USA, 105, 1425-1430, doi:10.1073/ pnas.0707386105.

Kaufman, D. S., and Coauthors, 2009: Recent warming reverses long-term Arctic cooling. Science, 325, 1236-1239, doi:10.1126/ science.1173983.

Kobashi, T., K. Kawamura, J. P. Severinghaus, J.-M. Barnola, T. Nakaegawa, B. M. Vinther, S. J. Johnsen, and J. E. Box, 2011: High variability of Greenland surface temperature over the past 4000 years estimated from trapped air in an ice core. Geophys. Res. Lett., 38, L21501, doi:10.1029/ 2011 GL049444.

Lacagnina, C., F. Selten, and A. P. Siebesma, 2014: Impact of changes in the formulation of cloud-related processes on model biases and climate feedbacks. J. Adv. Model. Earth Syst., 6, 1224-1243, doi:10.1002/2014MS000341.

Lamb, H. H., 1965: The early medieval warm epoch and its sequel. Palaeogeogr. Palaeoclimatol. Palaeoecol., 1, 13-37, doi:10.1016/ 0031-0182(65)90004-0.

Landrum, L., B. L. Otto-Bliesner, E. R. Wahl, A. Conley, P. J. Lawrence, N. Rosenbloom, and H. Teng, 2013: Last millennium climate and its variability in CCSM4. J. Climate, 26, 1085-1111, doi:10.1175/JCLI-D-11-00326.1.

Larsen, D. J., G. H. Miller, A. Geirsdottir, and T. Thordarson, 2011: A 3000-year varved record of glacier activity and climate change from the proglacial Lake Hvítárvatn, Iceland. Quat. Sci. Rev., 30, 2715-2731, doi:10.1016/j.quascirev.2011.05.026.

Lean, J., and D. Rind, 1999: Evaluating sun-climate relationships since the Little Ice Age. J. Atmos. Sol. Terr. Phys., 61, 25-36, doi:10.1016/S1364-6826(98)00113-8.

Lehner, F., A. Born, C. C. Raible, and T. F. Stocker, 2013: Amplified inception of European Little Ice Age by sea ice-oceanatmosphere feedbacks. J. Climate, 26, 7586-7602, doi:10.1175/ JCLI-D-12-00690.1.

Mann, M. E., R. S. Bradley, and M. K. Hughes, 1998: Global-scale temperature patterns and climate forcing over the past six centuries. Nature, 392, 779-787, doi:10.1038/33859.
- and Coauthors, 2009: Global signatures and dynamical origins of the Little Ice Age and Medieval Climate Anomaly. Science, 326, 1256-1260, doi:10.1126/science.1177303.

- J. D. Fuentes, and S. Rutherford, 2012: Underestimation of volcanic cooling in tree-ring-based reconstructions of hemispheric temperatures. Nat. Geosci., 5, 202-205, doi:10.1038/ ngeo1394.

Marcott, S. A., J. D. Shakun, P. U. Clark, and A. C. Mix, 2013: A reconstruction of regional and global temperature for the past 11,300 years. Science, 339, 1198-1201, doi:10.1126/science.1228026.

Massé, G., S. J. Rowland, M. A. Sicre, J. Jacob, E. Jansen, and S. T. Belt, 2008: Abrupt climate changes for Iceland during the last millennium: Evidence from high resolution sea ice reconstructions. Earth Planet. Sci. Lett., 269, 565-569, doi:10.1016/ j.epsl.2008.03.017.

Masson-Delmotte, V., and Coauthors, 2013: Information from paleoclimate archives. Climate Change 2013: The Physical Science Basis, T. F. Stocker et al., Eds., Cambridge University Press, 383-464. [Available online at https://www.ipcc.ch/pdf/ assessment-report/ar5/wg1/WG1AR5_Chapter05_FINAL.pdf.]

Miller, G. H., and Coauthors, 2012: Abrupt onset of the Little Ice Age triggered by volcanism and sustained by sea-ice/ocean feedbacks. Geophys. Res. Lett., 39, L02708, doi:10.1029/ 2011GL050168.

Myhre, G., E. J. Highwood, K. P. Shine, and F. Stordal, 1998: New estimates of radiative forcing due to well mixed greenhouse gases. Geophys. Res. Lett., 25, 2715-2718, doi:10.1029/98GL01908.

Ogilvie, A. E. J., and T. Jonsson, 2001: "Little Ice Age" research: A perspective from Iceland. Climatic Change, 48, 9-52, doi:10.1023/ A:1005625729889.

PAGES 2k Consortium, 2013: Continental-scale temperature variability during the past two millennia. Nat. Geosci., 6, 339346, doi:10.1038/ngeo1797.

Palastanga, V., G. van der Schrier, S. L. Weber, T. Kleinen, K. R. Briffa, and T. J. Osborn, 2011: Atmosphere and ocean dynamics: Contributors to the European Little Ice Age? Climate Dyn., 36, 973-987, doi:10.1007/s00382-010-0751-0.

Phipps, S. J., L. D. Rotstayn, H. B. Gordon, J. L. Roberts, A. C. Hirst, and W. F. Budd, 2012: The CSIRO Mk3L climate system model version 1.0 - Part 2: Response to external forcings. Geosci. Model Dev., 5, 649-682, doi:10.5194/gmd-5-649-2012.

Pongratz, J., C. Reick, T. Raddatz, and M. Claussen, 2008: A reconstruction of global agricultural areas and land cover for the last millennium. Global Biogeochem. Cycles, 22, GB3018, doi:10.1029/2007GB003153.

Pope, V. D., M. L. Gallani, P. R. Rowntree, and R. A. Stratton, 2000: The impact of new physical parametrizations in the Hadley Centre climate model: HadAM3. Climate Dyn., 16, 123-146, doi:10.1007/s003820050009.

Rotstayn, L. D., S. J. Jeffrey, M. A. Collier, S. M. Dravitzki, A. C. Hirst, J. I. Syktus, and K. K. Wong, 2012: Aerosol- and greenhouse gas-induced changes in summer rainfall and circulation in the Australasian region: A study using singleforcing climate simulations. Atmos. Chem. Phys., 12, 63776404, doi:10.5194/acp-12-6377-2012.

Schleussner, C. F., and G. Feulner, 2013: A volcanically triggered regime shift in the subpolar North Atlantic Ocean as a possible origin of the Little Ice Age. Climate Past, 9, 1321-1330, doi:10.5194/cp-9-1321-2013.

Schmidt, G. A., and Coauthors, 2006: Present-day atmospheric simulations using GISS ModelE: Comparison to in situ, satellite, and reanalysis data. J. Climate, 19, 153-192, doi:10.1175/ JCLI3612.1. 
, and Coauthors, 2011: Climate forcing reconstructions for use in PMIP simulations of the last millennium (v1.0). Geosci. Model Dev., 4, 33-45, doi:10.5194/gmd-4-33-2011.

, and Coauthors, 2012: Climate forcing reconstructions for use in PMIP simulations of the last millennium (v1.1). Geosci. Model Dev., 5, 185-191, doi:10.5194/gmd-5-185-2012.

Schurer, A. P., G. C. Hegerl, M. E. Mann, S. F. B. Tett, and S. J. Phipps, 2013: Separating forced from chaotic climate variability over the past millennium. J. Climate, 26, 6954-6973, doi:10.1175/JCLI-D-12-00826.1.

_ S. F. B. Tett, and G. C. Hegerl, 2014: Small influence of solar variability on climate over the past millennium. Nat. Geosci., 7, 104-108, doi:10.1038/ngeo2040.

Shapiro, A. I., W. Schmutz, E. Rozanov, M. Schoell, M. Haberreiter, A. V. Shapiro, and S. Nyeki, 2011: A new approach to the long-term reconstruction of the solar irradiance leads to large historical solar forcing. Astron. Astrophys. 529, A67, doi:10.1051/0004-6361/201016173.

Shell, K. M., J. T. Kiehl, and C. A. Shields, 2008: Using the radiative kernel technique to calculate climate feedbacks in NCAR's Community Atmospheric Model. J. Climate, 21, 2269-2282, doi:10.1175/2007JCLI2044.1.

Shindell, D. T., G. Faluvegi, R. L. Miller, G. A. Schmidt, J. E. Hansen, and S. Sun, 2006: Solar and anthropogenic forcing of tropical hydrology. Geophys. Res. Lett., 33, L24706, doi:10.1029/2006GL027468.

Sigl, M., and Coauthors, 2014: Insights from Antarctica on volcanic forcing during the common era. Nat. Climate Change, 4, 693697, doi:10.1038/nclimate2293.

Soden, B. J., and I. M. Held, 2006: An assessment of climate feedbacks in coupled ocean-atmosphere models. J. Climate, 19, 3354-3360, doi:10.1175/JCLI3799.1.

,,- R. Colman, K. M. Shell, J. T. Kiehl, and C. A. Shields, 2008: Quantifying climate feedbacks using radiative kernels. J. Climate, 21, 3504-3520, doi:10.1175/2007JCLI2110.1.

Steinhilber, F., J. Beer, and C. Froehlich, 2009: Total solar irradiance during the Holocene. Geophys. Res. Lett., 36, L19704, doi:10.1029/2009GL040142.

Stothers, R. B., 1984: The great Tambora eruption in 1815 and its aftermath. Science, 224, 1191-1198, doi:10.1126/ science.224.4654.1191.

Taylor, K. E., M. Crucifix, P. Braconnot, C. D. Hewitt, C. Doutriaux, A. J. Broccoli, J. F. B. Mitchell, and M. J. Webb,
2007: Estimating shortwave radiative forcing and response in climate models. J. Climate, 20, 2530-2543, doi:10.1175/ JCLI4143.1.

$\longrightarrow$, R. J. Stouffer, and G. A. Meehl, 2012: An overview of CMIP5 and the experiment design. Bull. Amer. Meteor. Soc., 93, 485498, doi:10.1175/BAMS-D-11-00094.1.

Timmreck, C., S. J. Lorenz, T. J. Crowley, S. Kinne, T. J. Raddatz, M. A. Thomas, and J. H. Jungclaus, 2009: Limited temperature response to the very large AD 1258 volcanic eruption. Geophys. Res. Lett., 36, L21708, doi:10.1029/ 2009GL040083.

Vial, J., J.-L. Dufresne, and S. Bony, 2013: On the interpretation of inter-model spread in CMIP5 climate sensitivity estimates. Climate Dyn., 41, 3339-3362, doi:10.1007/ s00382-013-1725-9.

Vieira, L. E. A., S. K. Solanki, N. A. Krivova, and I. Usoskin, 2011: Evolution of the solar irradiance during the Holocene. Astron. Astrophys., 531, A6, doi:10.1051/ 0004-6361/201015843.

Wanamaker, A. D., P. G. Butler, J. D. Scourse, J. Heinemeier, J. Eiriksson, K. L. Knudsen, and C. A. Richardson, 2012: Surface changes in the North Atlantic meridional overturning circulation during the last millennium. Nat. Commun., 3, 899, doi:10.1038/ncomms1901.

Wang, Y. M., J. L. Lean, and N. R. Sheeley, 2005: Modeling the sun's magnetic field and irradiance since 1713. Astrophys. J., 625, 522-538, doi:10.1086/429689.

Weber, S. L., 2005: A timescale analysis of the Northern Hemisphere temperature response to volcanic and solar forcing. Climate Past, 1, 9-17, doi:10.5194/cp-1-9-2005.

Yoshimori, M., T. Stocker, C. Raible, and M. Renold, 2005: Externally forced and internal variability in ensemble climate simulations of the Maunder Minimum. J. Climate, 18, 42534270, doi:10.1175/JCLI3537.1.

_ J. C. Hargreaves, J. D. Annan, T. Yokohata, and A. Abe-Ouchi, 2011: Dependency of feedbacks on forcing and climate state in physics parameter ensembles. J. Climate, 24, 6440-6455, doi:10.1175/2011JCLI3954.1.

Zhong, Y., G. H. Miller, B. L. Otto-Bliesner, M. M. Holland, D. A. Bailey, D. P. Schneider, and A. Geirsdottir, 2011: Centennial-scale climate change from decadally-paced explosive volcanism: A coupled sea ice-ocean mechanism. Climate Dyn., 37, 2373-2387, doi:10.1007/s00382-010-0967-z. 